\title{
Association of Polymorphisms in Mitofusin-2 Gene with Type 2 Diabetes in Han Chinese
}

\author{
Pengtao Li, Shuying Zhu, Xiaopan Wu, Xilin Zhu, Jingyun Li, Liping Pan, \\ Zhenhui Xin, Fenghe Niu, Jia Wu, and Ying Liu
} State Key Laboratory of Medical Molecular Biology, Institute of Basic Medical Sciences, Chinese Academy of Medical Sciences,
School of Basic Medicine, Peking Union Medical College, 5 Dongdan 3 Tiao, Beijing 100005, China

Correspondence should be addressed to Ying Liu, liuyingpumc@163.com

Received 6 March 2012; Revised 13 April 2012; Accepted 20 April 2012

Academic Editor: Sandro Massao Hirabara

Copyright () 2012 Pengtao Li et al. This is an open access article distributed under the Creative Commons Attribution License, which permits unrestricted use, distribution, and reproduction in any medium, provided the original work is properly cited.

MFN2 and ESRRA are candidate genes involved in the pathogenesis of T2D. Five tag-SNPs in MFN2 gene and three in ESRRA gene were selected and genotyped with TaqMan or PCR-RFLP method in stage 1 populations (555 patients with T2D and 649 control subjects) and stage 2 populations (546 patients with T2D versus 419 control subjects) in Han Chinese. And combining our published data, we estimated the interactions between genetic variants in the MFN2, ESRRA, and PGC-1 $\alpha$ genes on the T2D risk using MDR. $r 873458(G>A)$ and $\operatorname{rs} 2878677(C>T)$ in MFN2 gene were significantly associated with T2D $(P=0.005$ and 0.01 ) in stage 1 populations, and the association of other SNPs with T2D was not found. In stage 2 populations, we further confirmed the association between $\mathrm{rs} 2878677$ and T2D $(P=0.01)$. Combining the two stage populations, the data supported more significant effect of rs873458 and rs2878677 on T2D risk $(P=0.003$ and 0.0001$)$. A-C-G-T-C and G-T-C-T-C in $M F N 2$ had significant association with T2D $(P=0.007$ and 0.009$)$. The present study also provided the evidence that MFN2 had interactions with $P G C-1 \alpha(P<0.0001)$ or ESRRA $(P<0.0001)$. This study suggested a role of MFN2 polymorphism in the risk of T2D; however, further studies are needed.

\section{Introduction}

Type 2 diabetes (T2D) is a chronic disease characterized by high blood glucose which is induced by both insulin resistance and relative insulin deficiency [1], and the complications of T2D, such as cardiovascular disease, renal failure and blindness, always bring heavy burden to society. The latest studies from the International Diabetes Federation (IDF) reported that currently there were 366 million people with diabetes in the world by 2030 this number is expected to rise to 552 million with diabetes if no action is taken [2]. Some $90 \%$ of patients with diabetes have T2D, which is always as a result of a combination of lifestyle and genetic factors [3].

Peroxisome proliferator-activated receptor $\gamma$ coactivator $1 \alpha(P G C-1 \alpha)$ gene is originally identified as a coactivator of PPAR $\gamma$. It is a multifunctional regulatory factor involved in mitochondrial biosynthesis, $\beta$-oxidation of fatty acids, beta-cell insulin secretion, hepatic gluconeogenesis, glucose transport in muscle [4-6]. Our and other genetic association studies showed that the associations of $P G C-1 \alpha$ loci with T2D were found in different populations [7-10].

Recently, it was reported that estrogen-related receptor- $\alpha$ (ESRRA) protein binding PGC- $1 \alpha$ protein could regulate the expression of Mitofusin-2 (MFN2) gene by stimulating the activity of the MFN2 promoter [11]. ESRRA gene is located on chromosome 11q13. ESRRA gene is an orphan nuclear receptor (NR) belonging to the NR superfamily, group III, and it is a vital regulator involved in a wide variety of cell functions such as mitochondrial biogenesis, mitochondrial oxidative metabolism, carbohydrate metabolism, adaptive energy metabolism, and lipid metabolism [12-14]. Therefore, we hypothesize that ESRRA gene may be a candidate gene involved in the pathogenesis of T2D.

MFN2 gene maps on chromosome 1p36.22. MFN2 serve as a mitochondrial fusion protein regulating their morphology and distribution $[15,16]$. Tissues with high energetic requirement, such as skeletal muscle and heart, show high 
expression of MFN2 gene [17]. Some evidences demonstrated that it also played an important role in the oxidative metabolism [17] and ER-mitochondria juxtaposition [18], and repression of MFN2 gene reduced glucose oxidation, mitochondrial membrane potential, cell respiration, and mitochondrial proton leak [17]. In addition, the MFN2dependent mechanism of mitochondrial control is disturbed in skeletal muscle in animal or human obesity and in patients with T2D $[17,19]$, but no study has confirmed that MFN2 gene was associated with T2D.

In the present study, we evaluated the associations between the MFN2 and ESRRA genetic polymorphisms and T2D, and then combining our published data of $P G C-1 \alpha$ [7], we estimated the interactions between genetic variants in the MFN2, ESRRA, and PGC-1 $\alpha$ on the T2D risk in Han Chinese.

\section{Materials and Methods}

2.1. Subjects. The stage 1 populations are summarized in Table 1. The total of stage 1 populations comprised 1204 unrelated subjects, including 555 patients with T2D and 649 nondiabetic control subjects, ascertained from Han Chinese. All subjects were randomly enrolled from three top-grade hospitals in Beijing in 2010. Total case subjects were diagnosed according to the World Health Organization criteria (WHO 1998). As total control subjects, the age was between 35 and 70 years old, and they had normal fasting plasma glucose levels $(5.0 \pm 0.5 \mathrm{mmol} / \mathrm{L})$ without diabetic record or T2D family history. The genomic DNA was extracted from peripheral blood using QIAGEN kit. The clinical characteristics of stage 2 populations are also summarized in Table 1; it included 546 unrelated patients with T2D and 419 nodiabetic control subjects and of Han Chinese origin, as described previously [20]. All subjects provided written informed consent under protocols approved by the local ethics committee.

2.2. Single-Nucleotide Polymorphism (SNP) Selection and Genotyping. International HapMap Project SNP database (http://www.hapmap.org/) was implemented to search for SNPs in MFN2 and ESRRA gene. Using tagging with an $r^{2}>0.8$ and minor allele frequency (MAF) of $>5 \%$ and sequencing data in 20 nondiabetic control subjects, we selected 5 tag SNPs (rs873458, rs2878677, rs2236058, rs3766742, rs3766741) in MFN2 gene and 3 tag SNPs (rs731703, rs650008, rs11600990) in ESRRA gene; they were all located in intron region and could capture $100 \%$ of common variations across MFN2 and ESRRA gene region (containing 21 HapMap SNPs). 7 of 8 SNPs were successfully genotyped using the TaqMan method on a Bio-Rad iQ5 system. Primers and probes of rs873458C_8861262_10, rs3766741C_25606040_10 and rs650008 AHWR23M were purchased from Applied Biosystems, the others from Shanghai GeneCore BioTechnologies (primers showed in Table 2). Only one SNP ( $r s 3766742$ ) in the MFN2 was genotyped with PCR-restriction fragment-length polymorphism (PCR-RFLP) method, using the following primers (5'-AGCAGGACATGATAGGTTAG- $3^{\prime}$ and $5^{\prime}$ CACAGCTTGTCACAGTTTAG- $3^{\prime}$ ) and PCR Tm was $57^{\circ} \mathrm{C}$,
PCR product length is about $900 \mathrm{bp}$, and restriction enzyme (Hha I) provided by MBI Fermentas. A $10 \mu \mathrm{L}$ aliquot of PCR product was digested overnight at 37 in a $20 \mu \mathrm{L}$ reaction containing 5 units of Hha I. After overnight digestion, the products were separated on a 3\% agarose gel stained with ethidium bromide. TT genotypes were represented by a DNA band with a size of $900 \mathrm{bp}$, TC genotypes were represented by DNA bands with sizes of 900,700 , and $200 \mathrm{bp}$, and CC genotypes were represented by DNA bands with sizes of 700 and $200 \mathrm{bp}$. Call rates for all SNPs were $>99 \%$. 20 samples randomly selected from the whole sample bank were sequenced for 8 tag SNPs and the results showed excellent correspondence between sequencing and TaqMan genotyping or PCR-RFLP technique.

2.3. Statistical Methods. Genotype distributions for all studied SNPs were tested for Hardy-Weinberg equilibrium (HWE) by chi-square tests and no significant deviation was found in control subjects. Allele frequencies and genotype distributions, linkage disequilibrium (LD), and haplotypes were tested using the online software SHEsis (http://analysis .bio-x.cn/myAnalysis.php). Logistic regression analysis with additive model was used to adjust for sex, age, and body mass index (BMI), and the analysis was performed by SPSS (version 16.0). Tests for association between genotypes and quantitative traits were performed in control subjects using Kruskal-Wallis analysis of ranks for traits with nonnormal distribution or, alternatively, ANOVA for normally distribution in SPSS. We examined the analyses of genegene interactions on the risk of T2D using multifactor dimensionality reduction (MDR) version 2.0 beta 6 (http://www.epistasis.org/). $P$ value $<0.05$ is nominally significant.

\section{Results}

In stage 1 populations, we found that the $\mathrm{A}$ allele and $\mathrm{C}$ allele frequencies of rs873458 and rs2878677 of MFN2 gene in the diabetic group were lower than in the control group $(P=0.005, \mathrm{OR}=0.79,95 \% \mathrm{CI}=0.67-0.93 ; P=0.01, \mathrm{OR}=$ $0.81,95 \%$ CI $=0.68-0.95$ ) (Table 3); it showed A allele and C allele of rs873458 and rs2878677 of MFN2 gene confered protection agasist T2D. After adjusting for age, sex, and body mass index by using analysis of logistic regression with additive model, the results showed that the genotype distributions of rs873458 and rs2878677 of MFN2 gene also were significantly different in case-control subjects $(P c=$ $0.01, \mathrm{OR}=0.80,95 \% \mathrm{CI}=0.67-0.95 ; P c=0.02, \mathrm{OR}=0.83$, $95 \% \mathrm{CI}=0.71-0.97)($ Table 3$)$.

Replicating the two associated SNPs in stage 2 populations, data suggested that the C allele of rs 2878677 of MFN2 gene in the diabetic group was lower than in the control group $(P=0.01, \mathrm{OR}=0.79,95 \% \mathrm{CI}=0.65-0.94)$ (Table 3$)$. And it revealed that there was a borderline association between genotype distributions of rs873458 of MFN2 gene and type 2 diabetes (adjusted $P c=0.08, \mathrm{OR}=0.84,95 \% \mathrm{CI}=$ 0.69-1.02) (Table 3). Additionally, analyses in the combined populations showed that the allele frequencies and genotype distributions of rs873458 and rs2878677 of MFN2 gene had 
TABLE 1: Characteristics of the study populations.

\begin{tabular}{|c|c|c|c|c|}
\hline \multirow{2}{*}{ Characteristic } & \multicolumn{2}{|c|}{ Stage $1(n=1204)$} & \multicolumn{2}{|c|}{ Stage $2(n=965)$} \\
\hline & $\mathrm{T} 2 \mathrm{D}$ & Control & $\mathrm{T} 2 \mathrm{D}$ & Control \\
\hline Total (male \%) & $555(55.9)$ & $649(46.4)^{*}$ & $546(50.7)$ & $419(48.7)$ \\
\hline Age (years) & $53.6(8.2)$ & $50.5(8.5)^{*}$ & $58.8(11.8)$ & $63.2(8.2)^{*}$ \\
\hline $\operatorname{BMI}\left(\mathrm{kg} / \mathrm{m}^{2}\right)$ & $25.8(3.4)$ & $25.4(3.3)^{*}$ & $24.9(3.5)$ & $24.6(3.4)$ \\
\hline $\mathrm{DBP}(\mathrm{mmHg})$ & $82.7(11.4)$ & $79.7(11.8)^{*}$ & $80.3(11.0)$ & $75.6(10.1)^{*}$ \\
\hline SBP $(\mathrm{mmHg})$ & $129.6(18.5)$ & $128.3(16.9)$ & $131.4(19.2)$ & $127.7(17.2)$ \\
\hline FPG (mmol/L) & $9.0(2.9)$ & $5.0(0.5)^{*}$ & $9.2(3.2)$ & $5.0(0.5)^{*}$ \\
\hline $\mathrm{TG}(\mathrm{mmol} / \mathrm{L})$ & $2.1(2.3)$ & $1.6(1.1)^{*}$ & & \\
\hline IFCC-HbAlc $(\mathrm{mmol} / \mathrm{mol})$ & $63(19.0)$ & $41(3.0)^{*}$ & & \\
\hline DCCT-HbAlc (\%) & $7.9(1.7)$ & $5.9(0.3)^{*}$ & & \\
\hline
\end{tabular}

Data are means (SD), or male (\%), unless otherwise indicated. ${ }^{*} P<0.05$. BMI: body mass index; DBP: diastolic blood pressure; SBP: systolic blood pressure; FPG: fasting plasma glucose; TG: triglycerides; HbAlc: glycated haemoglobin $A_{1 c}$.

TABLE 2: Primers and probes of all SNPs.

\begin{tabular}{lll}
\hline SNPs ID & Primer $\left(5^{\prime}-3^{\prime}\right)$ & Probe $\left(5^{\prime}-3^{\prime}\right)$ \\
\hline \multirow{2}{*}{ rs2878677 } & F: GTGGAATAAAAGTTTTATGAATGGAG & P1: FAM-ATTCCACTTACGTGAGACaTCTAGAATAGTC-BHQ \\
& R: TAGCCATTAAACAATAACTCCCTG & P2: HEX-TCCACTTACGTGAGACgTCTAGAATAGTC-BHQ \\
rs2236058 & F: GGTGAGGAGGGCGGCT & P1: FAM-CTTCATCACCCCACCTGGTCTGTG-BHQ \\
& R: TGTGTTCAGGCTCTGAGAATGG & P2: HEX-CTTCATCACCCGACCTGGTCTGTG-BHQ \\
rs731703 & F: AGCCAGAGTCCCTGTTCGG & P1: FAM-TTGCTGTCCTGGCCAGTGTTCC-BHQ \\
& R: TGCTTCAGCCCCAGCTATG & P2: HEX-TTTGCTGTCCTGACCAGTGTTCCAG-BHQ \\
rs11600990 & F: AAGTCATTGTTCTTCCCTAAGCCTC & P1: FAM-TGCTACCGTCACTGAG-MGB \\
& R: GAGGTGTCTCCGTAAGGTCTTCA & P2: HEX-TGCTACCATCACTGAGT-MGB \\
\hline
\end{tabular}

more significant effects on type 2 diabetes susceptibility $(P=0.002, \mathrm{OR}=0.83,95 \% \mathrm{CI}=0.73-0.93 ; P=0.0001$, $\mathrm{OR}=0.79,95 \% \mathrm{CI}=0.69-0.89$ and adjusted $P c=0.002$, $\mathrm{OR}=0.82,95 \% \mathrm{CI}=0.72-0.93 ; \mathrm{Pc}=0.0004, \mathrm{OR}=0.81$, 95\% CI $=0.72-0.91$ ) (Table 3 ). No significant association of other SNPs in MFN2 or ESRRA gene with type 2 diabetes was found (See Supplementary Table 1 in Supplementary material available online at doi:10.1155/2012/205752).

Analyses of association between haplotypes and phenotypes were performed in nondiabetic control subjects, for most patients with T2D included in the present study had medical treatments, which may affect the real parameters. We found that the genotype distributions of SNPs in MFN2 and ESRRA gene in control subjects displayed no significant association with quantitative traits of type 2 diabetes including body mass index, diastolic blood pressure, systolic blood pressure, fasting plasma glucose, triglycerides, and glycated haemoglobin A1c (data not shown).

We further examined the degree of linkage disequilibrium of SNPs in MFN2 and ESRRA gene (Supplementary Tables 2 and 3). To test whether haplotypes represent the causal variants better than single SNPs, we estimated the frequencies of haplotypes between the case-control subjects in stage 1 populations (all those frequencies $<0.03$ were ignored). It was showed that A-C-G-T-C and G-T-C-T-C in MFN2 gene were significantly associated with T2D $(P=$ $0.007, \mathrm{OR}=0.79,95 \% \mathrm{CI}=0.66-0.94 ; P=0.009$, OR $=$ 1.26 , 95\% CI $=1.06-1.49$ ) (Table 4 ), while the frequencies of haplotypes in ESRRA gene did not significantly differ in case-control subjects (data not shown).

The results of the exhaustive MDR analysis are summarized in Table 5. The model was considered to be statistically significant with a testing accuracy $>50 \%$ and $P<0.05$ via permutation test of 1000 iterations. The rs2878677/rs3766741/rs731703/rs11600990 model $(P<$ $0.0001)$ in MFN2-ESRRA from stage 1 populations, the rs2878677/rs3774923/rs7656250 model $(P<0.0001)$ and the rs2878677/rs3774923/rs7656250/rs13131226 model $(P<$ $0.0001)$ in $M F N 2-P G C-1 \alpha$ gene from stage 2 populations (shown in Table 5), data of $P G C-1 \alpha$ gene from our previously study [7], suggest that there are interactions between genetic variants in the MFN2, ESRRA, and PGC-1 $\alpha$ gene.

\section{Discussion}

In the present study, we examined eight common variants in MFN2 and ESRRA genes and confirmed that $G$ allele of rs873458 and T allele of rs2878677in MFN2 gene are associated with higher T2D risk compared with $\mathrm{A}$ and $\mathrm{C}$ allele, respectively. Consistently, in haplotypes analyses of MFN2 gene, results show that individuals carrying G-T-C-T$\mathrm{C}$ present increased T2D risk compared with those carrying A-C-G-T-C.

Because rs873458 and rs2878677 map within intron 2 and 3 , it is difficult for us to shed light on their downstream consequences, given our rudimentary knowledge of the 
TABLE 3: Allele frequencies and genotype distributions of rs873458 and rs2878677 in MFN2 gene among stage 1 and stage 2 populations.

\begin{tabular}{|c|c|c|c|c|c|c|c|c|c|c|c|}
\hline & \multirow{2}{*}{ SNP } & \multicolumn{5}{|c|}{ Genotype } & \multicolumn{5}{|c|}{ Allele } \\
\hline & & & $\mathrm{T} 2 \mathrm{D}(\%)$ & Control (\%) & $P / P c$ & $\begin{array}{c}\text { OR } \\
(95 \% \mathrm{CI})\end{array}$ & & T2D (\%) & $\begin{array}{l}\text { Control } \\
(\%)\end{array}$ & $P$ & $\begin{array}{c}\text { OR } \\
(95 \% \mathrm{CI})\end{array}$ \\
\hline \multirow{8}{*}{ Stage 1} & rs873458 & & 555 & 638 & \multirow{4}{*}{$0.0007 / 0.01$} & \multirow{4}{*}{$\begin{array}{c}0.80 \\
(0.67-0.95)\end{array}$} & & & & \multirow{4}{*}{0.005} & \multirow{3}{*}{$\begin{array}{c}0.79 \\
(0.67-0.93)\end{array}$} \\
\hline & \multirow{7}{*}{ rs2878677 } & $\mathrm{A} / \mathrm{A}$ & $50(9.0)$ & $105(16.5)$ & & & A & $382(34.4)$ & $510(40.0)$ & & \\
\hline & & $\mathrm{A} / \mathrm{G}$ & $282(50.8)$ & $300(47.0)$ & & & G & $728(65.6)$ & $766(60.0)$ & & \\
\hline & & $\mathrm{G} / \mathrm{G}$ & $223(40.2)$ & $233(36.5)$ & & & & & & & \\
\hline & & & 549 & 643 & \multirow{4}{*}{$0.03 / 0.02$} & \multirow{4}{*}{$\begin{array}{c}0.83 \\
(0.71-0.97)\end{array}$} & & & & \multirow{4}{*}{0.01} & \multirow{4}{*}{$\begin{array}{c}0.81 \\
(0.68-0.95)\end{array}$} \\
\hline & & $\mathrm{T} / \mathrm{T}$ & $124(22.6)$ & $108(16.8)$ & & & $\mathrm{T}$ & $487(44.4)$ & $503(39.1)$ & & \\
\hline & & $\mathrm{C} / \mathrm{T}$ & $239(43.5)$ & $287(44.6)$ & & & $\mathrm{C}$ & $611(55.6)$ & 783 (60.9) & & \\
\hline & & $\mathrm{C} / \mathrm{C}$ & $186(33.9)$ & $248(38.6)$ & & & & & & & \\
\hline \multirow{8}{*}{ Stage 2} & rs873458 & & 539 & 412 & \multirow{4}{*}{$0.21 / 0.08$} & \multirow{4}{*}{$\begin{array}{c}0.84 \\
(0.69-1.02)\end{array}$} & & & & \multirow{3}{*}{0.16} & \multirow{3}{*}{$\begin{array}{c}0.87 \\
(0.72-1.05)\end{array}$} \\
\hline & \multirow{7}{*}{ rs 2878677} & $\mathrm{~A} / \mathrm{A}$ & $72(13.4)$ & $58(14.1)$ & & & A & $386(35.8)$ & $321(39.0)$ & & \\
\hline & & $\mathrm{A} / \mathrm{G}$ & $242(44.9)$ & $205(49.8)$ & & & G & $692(64.2)$ & $503(61.0)$ & & \\
\hline & & $\mathrm{G} / \mathrm{G}$ & $225(41.7)$ & $149(36.2)$ & & & & & & & \\
\hline & & & 545 & 417 & \multirow{4}{*}{$0.05 / 0.02$} & \multirow{4}{*}{$\begin{array}{c}0.80 \\
(0.67-0.97)\end{array}$} & & & & \multirow{4}{*}{0.01} & \multirow{4}{*}{$\begin{array}{c}0.79 \\
(0.65-0.94)\end{array}$} \\
\hline & & $\mathrm{T} / \mathrm{T}$ & $135(24.8)$ & $78(18.7)$ & & & $\mathrm{T}$ & $516(47.8)$ & $348(41.8)$ & & \\
\hline & & $\mathrm{C} / \mathrm{T}$ & $248(45.5)$ & $192(46.0)$ & & & $\mathrm{C}$ & $564(52.2)$ & $484(58.2)$ & & \\
\hline & & $\mathrm{C} / \mathrm{C}$ & $162(29.7)$ & $147(35.3)$ & & & & & & & \\
\hline \multirow{8}{*}{ Combinded } & rs873458 & & 1094 & 1050 & \multirow{4}{*}{$0.005 / 0.002$} & \multirow{4}{*}{$\begin{array}{c}0.82 \\
(0.72-0.93)\end{array}$} & & & & \multirow{4}{*}{0.002} & \multirow{3}{*}{$\begin{array}{c}0.83 \\
(0.73-0.93)\end{array}$} \\
\hline & & $\mathrm{A} / \mathrm{A}$ & $122(11.2)$ & $163(15.5)$ & & & A & $768(35.1)$ & 831 (39.6) & & \\
\hline & & $\mathrm{A} / \mathrm{G}$ & $524(47.9)$ & $505(48.1)$ & & & G & $1420(64.9)$ & $1269(60.4)$ & & \\
\hline & & $\mathrm{G} / \mathrm{G}$ & $448(41.0)$ & $382(36.4)$ & & & & & & & \\
\hline & \multirow[t]{4}{*}{ rs2878677 } & & 1089 & 1059 & \multirow{4}{*}{$0.0006 / 0.0004$} & & & & & & \\
\hline & & $\mathrm{T} / \mathrm{T}$ & $259(23.8)$ & $186(17.6)$ & & $\begin{array}{c}0.81 \\
(0.72-0.91)\end{array}$ & $\mathrm{T}$ & $1003(46.1)$ & $851(40.2)$ & 0.0001 & $\begin{array}{c}0.79 \\
(0.69-0.89)\end{array}$ \\
\hline & & $\mathrm{C} / \mathrm{T}$ & $485(44.5)$ & $479(45.2)$ & & & $\mathrm{C}$ & $1183(53.9)$ & $1267(59.8)$ & & \\
\hline & & $\mathrm{C} / \mathrm{C}$ & 345 (31.7) & $394(37.2)$ & & & & & & & \\
\hline
\end{tabular}

$P$ had no adjustment, whereas $P c$ were adjusted for age, sex, and BMI.

TABLE 4: Common haplotypes in the MFN2 gene.

\begin{tabular}{lcccc}
\hline Haplotype & T2D (\%) & Control (\%) & $P$ & OR (95\% CI) \\
\hline A-C-G-T-C & $347.95(31.9)$ & $474.88(37.7)$ & 0.007 & $0.79(0.66-0.94)$ \\
G-C-C-C-C & $66.82(6.1)$ & $100.87(8.0)$ & 0.10 & $0.76(0.55-1.05)$ \\
G-C-C-T-C & $35.18(3.2)$ & $40.09(3.2)$ & 0.90 & $1.03(0.65-1.63)$ \\
G-C-G-T-G & $114.87(10.5)$ & $111.74(8.9)$ & 0.14 & $1.23(0.94-1.62)$ \\
G-T-C-T-C & $443.08(40.6)$ & $454.77(36.2)$ & 0.009 & $1.26(1.06-1.49)$ \\
others & $84.1(7.7)$ & $75.65(6.0)$ & & \\
\hline Total & $1092(100 \%)$ & $1258(100 \%)$ & \\
\hline
\end{tabular}

Haplotype analysis was conducted with rs873458, rs2878677, rs2236058, rs3766742, rs3766741. $P$ had no adjustment.

TABLE 5: Models of multi-loci interaction on the risk of T2D by MDR.

\begin{tabular}{|c|c|c|c|c|}
\hline Gene-gene & Combination of multiloci & ${ }^{*} P$ value & CV consistency & Testing accuracy $(\%)$ \\
\hline \multirow{3}{*}{ MFN2-ESRRA } & rs873458/rs3766742 & 0.0007 & $7 / 10$ & 56.1 \\
\hline & rs873458/rs2878677/rs3766741 & $<0.0001$ & $4 / 10$ & 56.2 \\
\hline & rs2878677/rs3766741/rs731703/rs11600990 & $<0.0001$ & $3 / 10$ & 57.7 \\
\hline \multirow{3}{*}{ MFN2-PGC-1 $\alpha$} & rs7656250/rs13131226 & 0.0002 & $7 / 10$ & 56.4 \\
\hline & rs2878677/rs3774923/rs7656250 & $<0.0001$ & $10 / 10$ & 59.9 \\
\hline & rs2878677/rs3774923/rs7656250/rs13131226 & $<0.0001$ & $9 / 10$ & 63.9 \\
\hline
\end{tabular}

Rs873458, rs2878677, rs3766742, rs3766741 located in MFN2, rs731703 and rs11600990 located in ESRRArs7656250, rs13131226, and rs3774923 located in $P G C-1 \alpha$. $P$ value based on 1,000 permutations. 
mechanics of gene regulation. In multifactorial disease, most susceptibility variants, mapping outside the coding regions of genes, are assumed to influence transcript regulation rather than gene function [21]. Locations of rs873458 and rs 2878677 are surrounded by the regions coding the GTPase domain of MFN2 which drive GTP hydrolysis to provide energy for the mitochondrial fusion activity induced by MFN2 [16, 22]. In addition, MFN2 gene is the first structural tether identified gene in the molecular basis of ER-mitochondria juxtaposition, it has a role in the intercommunication during $\mathrm{Ca}^{2+}$ signaling [18]. A study revealed that ablation or silencing of MFN2 gene in mouse embryonic fibroblasts or HeLa cell created confusion in ER morphology and increased distance between the ER and mitochondria, hence retarding the mitochondrial $\mathrm{Ca}^{2+}$ uptake [18], which may lead to insulin secretion disorder and insulin resistance. Besides, positive correlation was observed between the expression of MFN2 gene and insulin sensitivity [23]. In addition, the MFN2-dependent mechanism of mitochondrial control is disturbed in skeletal muscle in animal or human obesity, and in patients with T2D [17, 19]. It is possible that the associated SNPs may be in strong linkage disequilibrium with unidentified causal variant(s) that may regulate the expression or function of MFN2 gene.

Although many genomewide association studies (GWASs) of T2D are now emerging, MFN2 gene is not involved. Indeed, the effect sizes of the known, common variants influencing the risk of type 2 diabetes are modest, and the proportion of overall predisposition explained is approximately 5 to $10 \%$ for T2D [24]. It has been found that T2D loci identified by linkage analyses and GWAS lack the correlation of T2D [25]. Additionally, most of them were conducted in Caucasians. Differences in genetic background, risk-factor profile, environment, and study design may lead to ethnic differences in susceptibility loci [26]. Different allele frequencies of rs873458 and rs 2878677 among the HapMap populations indicate that differences in genetic architecture may play a role (Supplementary Table 4). Therefore, further studies including GWAS are needed to confirm our findings.

ESRRA is an orphan nuclear receptor, it could regulate a number of downstream genes to control energy balance in animals. ESRRA gene KO mice showed altered expression of several target genes implicated in the regulation of adipogenesis and energy metabolism [27]. However, in the present study, no association between the phenotypes of T2D, such as BMI, was found. Our data also showed that there were three common variants (rs731703, rs650008, rs11600990) in ESRRA in Han Chinese populations, while only one common variant rs11600990 was found in Danish populations [28]. The analysis of rs11600990 in the two populations is consistent. Three tag SNPs could capture $100 \%$ of common variations (MAF > 5\%) across ESRRA gene region, but we cannot exclude rare causal genetic polymorphisms in ESRRA gene, for the rare variations may be responsible for disease [29-31].
$P G C-1 \alpha$ is an important transcriptional coactivator involved in the regulation of genes related to energy metabolism [32]. Mice lacking $P G C-1 \alpha$ developed fasting hepatic steatosis which may lead to lower rates of fatty acid oxidation that might play a causative role to develop insulin resistance $[33,34]$. In addition, PGC- $1 \alpha$ maintained higher number of active mitochondria and OXPHOS proteins that were reduced in T2D subjects. As it relates to the human genetics, several SNPs of $P G C-1 \alpha$ gene in certain populations were associated with T2D in certain populations [7-10]. The analysis of association between $P G C-1 \alpha$ gene and T2D has been published in our previous paper [7].

In addition, it was found that the interactions between genetic variants of the MFN2-ESRRA and MFN2-PGC-1 $\alpha$ in the pathogenesis of type 2 diabetes. Moreover, a positive result of association analyses regarding single SNP rs 2878677 in MFN2 gene indicates MFN2 gene may be the main factor during the interaction and has an important role in the pathogenesis of T2D. It is consistent with the study that it proved the interactions between MFN2, ESRRA, and PGC$1 \alpha$ proteins, which revealed the stimulatory effect of PGC- $1 \alpha$ on the activity of MFN2 gene needed to integrate the ESRRA, ESRRA, and PGC- $1 \alpha$ caused a synergic effect on activity of the MFN2 gene expression, and the stimulatory effect of $P G C-1 \alpha$ gene on mitochondrial membrane potential can be weakened by MFN2 loss of function [11]. Therefore, further studies are needed to explore the functions and interactions of the MFN2, ESRRA, and PGC-1 $\alpha$ genes.

In most patients, T2D is due to alterations of many genes, each of which has a partial and additive effect [35]. Consequently, we hypothesize that these three genes may serve as partial or additive factors leading to T2D, while the intrinsic mechanism is unknown. Functional studies, multiplex-gene analyses, and computational biology are needed to further characterization of their interactions in the pathogenesis of T2D.

However, some limitations should be noted in the present study. First, the effect of gene-environment interactions was not evaluated; environmental risk factors may influence the effect estimates. Second, given the study samples were relatively small, we need to replicate our finding in additional samples in future studies. Third, clinical characteristics were not defined strictly.

In conclusion, the present analysis shows that MFN2 gene has significant associations with T2D in Han Chinese. It may represent a potential explanation for T2D. But more studies with different ethnic populations are needed to verify this finding and the intrinsic mechanism is expected to be uncovered.

\section{Conflict of Interests}

The authors have no conflict of interests to declare.

\section{Acknowledgments}

The authors thank all the participants of this research. This study was supported by the Science Fund for Creative Research Groups (no. 30721063) and Genome-Wide 
Association Studies of T2D and Pharmacogenomics Study (2009AA022704).

\section{References}

[1] V. Kumar, N. Fausto, A. K. Abbas, R. S. Cotran, and S. L. Robbins, Robbins and Cotran Pathologic Basis of Disease, 7th edition, 2005.

[2] I. D. Federation, Global Diabetes Plan 2011-2021, 2011.

[3] U. Risérus, W. C. Willett, and F. B. Hu, "Dietary fats and prevention of type 2 diabetes," Progress in Lipid Research, vol. 48, no. 1, pp. 44-51, 2009.

[4] J. C. Yoon, G. Xu, J. T. Deeney et al., "Suppression of $\beta$ cell energy metabolism and insulin release by PGC- $1 \alpha$," Developmental Cell, vol. 5, no. 1, pp. 73-83, 2003.

[5] S. Soyal, F. Krempler, H. Oberkofler, and W. Patsch, "PGC- $1 \alpha$ : a potent transcriptional cofactor involved in the pathogenesis of type 2 diabetes," Diabetologia, vol. 49, no. 7, pp. 1477-1488, 2006.

[6] Z. Wu, P. Puigserver, U. Andersson et al., "Mechanisms controlling mitochondrial biogenesis and respiration through the thermogenic coactivator PGC-1," Cell, vol. 98, no. 1, pp. 115124, 1999.

[7] S. Zhu, Y. Liu, X. Wang et al., "Evaluation of the association between the PPARGC1A genetic polymorphisms and type 2 diabetes in Han Chinese population," Diabetes Research and Clinical Practice, vol. 86, no. 3, pp. 168-172, 2009.

[8] A. Bhat, A. Koul, E. Rai, S. Sharma, M. K. Dhar, and R. N. K. Bamezai, "PGC-1 $\alpha$ Thr394Thr and Gly482Ser variants are significantly associated with T2DM in two North Indian populations: a replicate case-control study," Human Genetics, vol. 123, no. 1, p. 115, 2008.

[9] R. E. Pratley, D. B. Thompson, M. Prochazka et al., "An autosomal genomic scan for loci linked to prediabetic phenotypes in pima indians," Journal of Clinical Investigation, vol. 101, no. 8, pp. 1757-1764, 1998.

[10] J. Ek, G. Andersen, S. A. Urhammer et al., "Mutation analysis of peroxisome proliferator-activated receptor- $\gamma$ coactivator- 1 (PGC-1) and relationships of identified amino acid polymorphisms to Type II diabetes mellitus," Diabetologia, vol. 44, no. 12, pp. 2220-2226, 2001.

[11] F. X. Soriano, M. Liesa, D. Bach, D. C. Chan, M. Palacín, and A. Zorzano, "Evidence for a mitochondrial regulatory pathway defined by peroxisome proliferator-activated receptor- $\gamma$ coactivator- $1 \alpha$, estrogen-related receptor- $\alpha$, and mitofusin 2 ," Diabetes, vol. 55, no. 6, pp. 1783-1791, 2006.

[12] V. Giguere, N. Yang, P. Segui, and R. M. Evans, "Identification of a new class of steroid hormone receptors," Nature, vol. 331, no. 6151, pp. 91-94, 1988.

[13] R. Sladek, J. A. Bader, and V. Giguère, "The orphan nuclear receptor estrogen-related receptor or $\alpha$ is a transcriptional regulator of the human medium-cha $\mathrm{n}$ Acyl coenzyme A dehydrogenase gene," Molecular and Cellular Biology, vol. 17, no. 9, pp. 5400-5409, 1997.

[14] H. S. Ranhotra, "The estrogen-related receptor alpha: the oldest, yet an energetic orphan with robust biological functions," Journal of Receptors and Signal Transduction, vol. 30, no. 4, pp. 193-205, 2010.

[15] M. Rojo, F. Legros, D. Chateau, and A. Lombès, "Membrane topology and mitochondrial targeting of mitofusins, ubiquitous mammalian homologs of the transmembrane GTPase Fzo," Journal of Cell Science, vol. 115, no. 8, pp. 1663-1674, 2002.
[16] A. Santel and M. T. Fuller, "Control of mitochondrial morphology by a human mitofusin," Journal of Cell Science, vol. 114, no. 5, pp. 867-874, 2001.

[17] D. Bach, S. Pich, F. X. Soriano et al., "Mitofusin-2 determines mitochondrial network architecture and mitochondrial metabolism: a novel regulatory mechanism altered in obesity," Journal of Biological Chemistry, vol. 278, no. 19, pp. 1719017197, 2003.

[18] O. M. de Brito and L. Scorrano, "Mitofusin 2 tethers endoplasmic reticulum to mitochondria," Nature, vol. 456, no. 7222, pp. 605-610, 2008.

[19] D. Bach, D. Naon, S. Pich et al., "Expression of Mfn2, the Charcot-Marie-Tooth neuropathy type 2A gene, in human skeletal muscle: effects of type 2 diabetes, obesity, weight loss, and the regulatory role of tumor necrosis factor $\alpha$ and interleukin-6," Diabetes, vol. 54, no. 9, pp. 2685-2693, 2005.

[20] Y. Liu, Y. Liu, N. Niu et al., "Genetic variation and association analyses of the nuclear respiratory factor 1 (nRF1) gene in Chinese patients with type 2 diabetes," Diabetes, vol. 57, no. 3, pp. 777-782, 2008.

[21] M. I. McCarthy, "Genomics, type 2 diabetes, and obesity," The New England Journal of Medicine, vol. 363, no. 24, pp. 23392350, 2010.

[22] A. Santetl, S. Frank, B. Gaume, M. Herrler, R. J. Youle, and M. T. Fuller, "Mitofusin-1 protein is a generally expressed mediator of mitochondrial fusion in mammalian cells," Journal of Cell Science, vol. 116, no. 13, pp. 2763-2774, 2003.

[23] A. Gesing, A. Bartke, F. Wang, M. Karbownik-Lewinska, and M. M. Masternak, "Key regulators of mitochondrial biogenesis are increased in kidneys of growth hormone receptor knockout (GHRKO) mice," Cell Biochemistry and Function, vol. 29, no. 6, pp. 459-467, 2011.

[24] B. F. Voight, L. J. Scott, V. Steinthorsdottir et al., "Twelve type 2 diabetes susceptibility loci identified through largescale association analysis," Nature Genetics, vol. 42, no. 7, pp. 579-589, 2010.

[25] S. Lillioja and A. Wilton, "Agreement among type 2 diabetes linkage studies but a poor correlation with results from genome-wide association studies," Diabetologia, vol. 52, no. 6, pp. 1061-1074, 2009.

[26] Z. Al-Hamodi, I. S. Ismail, R. Saif-Ali, K. A. Ahmed, and S. Muniandy, "Association of plasminogen activator inhibitor1 and tissue plasminogen activator with type 2 diabetes and metabolic syndrome in Malaysian subjects," Cardiovascular Diabetology, vol. 10, article R23, 2011.

[27] J. Luo, R. Sladek, J. Carrier, J. A. Bader, D. Richard, and V. Giguère, "Reduced fat mass in mice lacking orphan nuclear receptor estrogen-related receptor $\alpha$," Molecular and Cellular Biology, vol. 23, no. 22, pp. 7947-7956, 2003.

[28] L. H. Larsen, C. S. Rose, T. Sparsø et al., "Genetic analysis of the estrogen-related receptor $\alpha$ and studies of association with obesity and type 2 diabetes," International Journal of Obesity, vol. 31, no. 2, pp. 365-370, 2007.

[29] I. M. Frayling, N. E. Beck, M. Ilyas et al., "The APC variants I1307K and E1317Q are associated with colorectal tumors, but not always with a family history," Proceedings of the National Academy of Sciences of the United States of America, vol. 95, no. 18, pp. 10722-10727, 1998.

[30] G. Gibson, "Rare and common variants: twenty arguments," Nature Reviews Genetics, vol. 13, no. 2, pp. 135-145, 2012.

[31] Y.-L. Yang, W.-P. Chang, Y.-W. Hsu et al., "Lack of association between clec5a gene single-nucleotide polymorphisms and kawasaki disease in taiwanese children," Journal of Biomedicine and Biotechnology, vol. 2012, Article ID 398628, 2012. 
[32] P. Puigserver and B. M. Spiegelman, "Peroxisome proliferatoractivated receptor- $\gamma$ coactivator $1 \alpha$ (PGC- $1 \alpha$ ): transcriptional coactivator and metabolic regulator," Endocrine Reviews, vol. 24, no. 1, pp. 78-90, 2003.

[33] J. Lin, P. H. Wu, P. T. Tarr et al., "Defects in adaptive energy metabolism with CNS-linked hyperactivity in PGC- $1 \alpha$ null mice," Cell, vol. 119, no. 1, pp. 121-135, 2004.

[34] T. C. Leone, J. J. Lehman, B. N. Finck et al., "PGC-1alpha deficiency causes multi-system energy metabolic derangements: muscle dysfunction, abnormal weight control and hepatic steatosis," PLoS Biology, vol. 3, no. 4, Article ID e101, 2005.

[35] S. C. Elbein, "Perspective: the search for genes for type 2 diabetes in the post-genome era," Endocrinology, vol. 143, no. 6, pp. 2012-2018, 2002. 

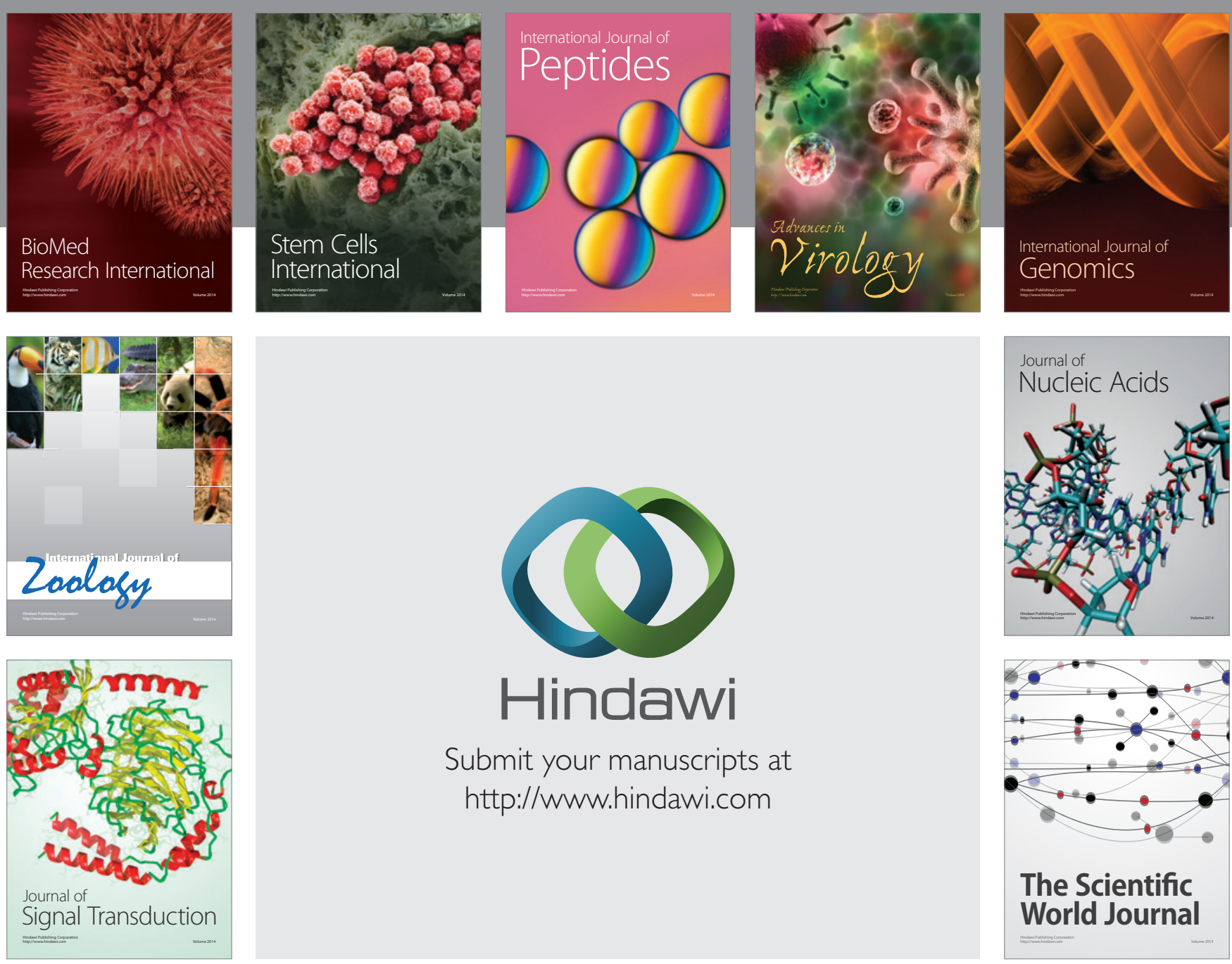

Submit your manuscripts at

http://www.hindawi.com
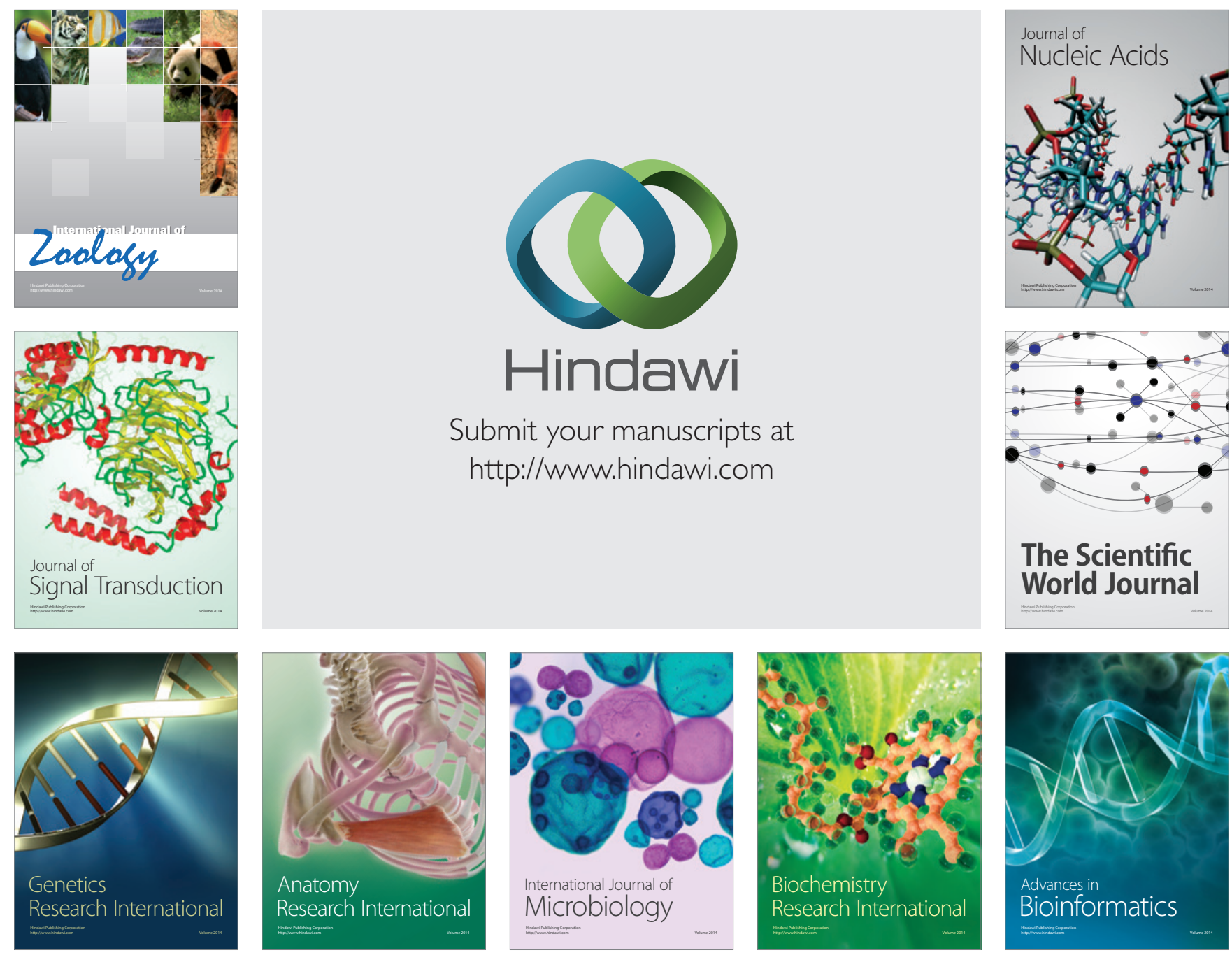

The Scientific World Journal
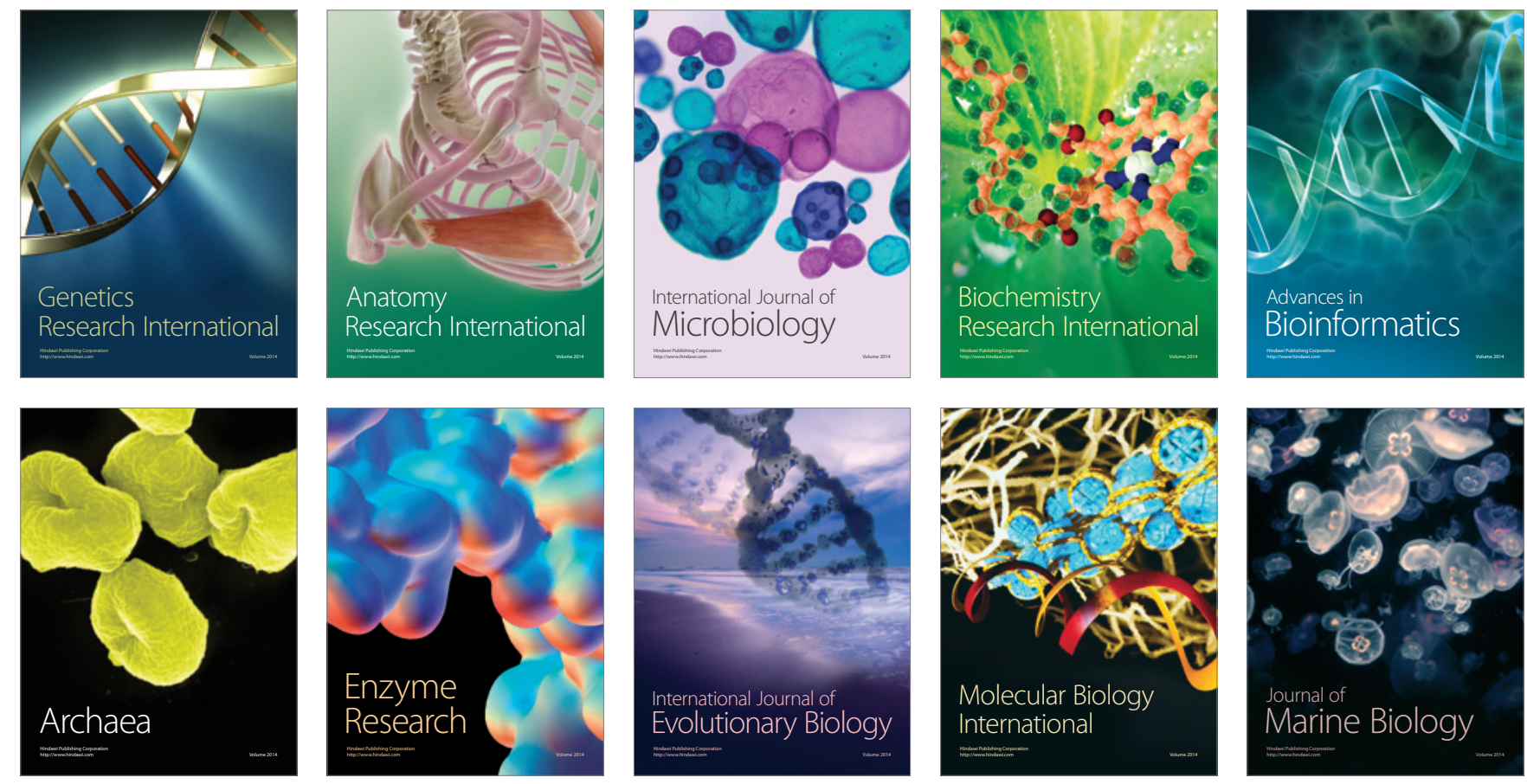